\title{
AS REPRESENTAÇÓES SOCIAIS DOS PROFESSORES DE EDUCAÇÃO FÍSICA DIANTE DA BASE NACIONAL COMUM CURRICULAR
}

\author{
Carlos Eduardo Lima dos Santos ${ }^{1}$ \\ Ednaldo da Silva Pereira Filho ${ }^{2}$
}

\begin{abstract}
Resumo: O presente estudo teve por objetivo descrever e analisar as representaçóes sociais dos professores de Educação Física da rede municipal de Gravataí/RS, diante da Base Nacional Comum Curricular (BNCC). Trata-se de uma pesquisa quanti-qualitativa, que se utilizou de questionários eletrônicos e entrevistas semiestruturadas destinados aos professores desta área de conhecimento das escolas das regiôes distritais desse município. Os resultados mostraram que os profissionais de Educação Física encaram como principais dificuldades os fatores associados à estrutura física e/ou materiais das escolas, além da falta de domínio em certos conteúdos, apresentando, também, críticas e opinióes contrastantes a respeito do documento. Todavia, os professores participantes reconhecem a importância da BNCC, principalmente em razão da padronização do ensino, a adição de elementos específicos das habilidades e competências abordadas, além de uma melhor organização e orientação para os docentes.
\end{abstract}

Palavras-chave: Representações Sociais; BNCC; Professores; Educação Física Escolar.

\section{THE SOCIAL REPRESENTATIONS OF PHYSICAL EDUCATION TEACHERS BEFORE THE COMMON CURRICULAR NATIONAL BASE}

\begin{abstract}
The present study aimed to describe and analyze the social representations of Physical Education teachers from the municipal network of Gravataí / RS, in front of the National Common Curricular Base (BNCC). This is a quantitative and qualitative research, which used electronic questionnaires and semi-structured interviews for teachers in this area of knowledge in schools in the district regions of that municipality. The results showed that Physical Education professionals face as
\end{abstract}

1 Professor de Educação Física, graduado pela Universidade do Vale do Rio dos Sinos - UNISINOS. E-mail: carlos.profissionalef@gmail.com.

2 Professor de Educaçáo Física e Doutor em Ciências Sociais pela UNISINOS. E-mail: ednaldo@unisinos.br. 
main difficulties the factors associated with the physical structure and / or materials of the schools, in addition to the lack of mastery in certain contents, also presenting criticisms and contrasting opinions about the document. However, participating teachers recognize the importance of BNCC, mainly due to the standardization of teaching, the addition of specific elements of the skills and competencies addressed, in addition to better organization and guidance for teachers.

Keywords: Social Representations; BNCC; Teachers; School Physical Education.

\section{INTRODUÇÃO}

Homologada no ano de 2017 para as etapas de Ensino Infantil, Ensino Fundamental I e Ensino Fundamental II, e em 2018 para a etapa do Ensino Médio, a Base Nacional Comum Curricular (BNCC) vem sendo um tema bastante recorrente em debates de cunho educacional. Professores, gestores, universitários e especialistas na área da Educaçáo convergem e/ou divergem nos mais variados aspectos do documento, que veio para detalhar o compromisso da Educação Básica na garantia da aprendizagem de conhecimentos comuns para toda a população brasileira. Com isso temos um verdadeiro marco normativo na área da educação que, pretensamente, deve articular e complementar os preceitos constitucionais, os princípios e finalidades da Lei de Diretrizes e Bases da Educação Nacional (1996) as Diretrizes Curriculares Nacionais (2013), revisitar alguns aspectos dos Parâmetros Curriculares Nacionais (1997) e, finalmente, materializar-se na BNCC (2017) como a grande referência para as elaboraçóes dos planejamentos pedagógicos de cada professor(a) brasileiro.

A elaboração e a consequente aplicação do novo documento refletem diretamente na atuação dos docentes, independentemente da sua área de formação. A modificação, adição e/ou subtração de conteúdo $(\mathrm{s})$ altera $(\mathrm{m})$ o quadro curricular e as propostas de abordagens podem entrar em conflito com as que já são efetuadas nas escolas e já possuem uma certa legitimidade entre os profissionais.

O município de Gravataí/RS, em 2019, passou a aderir a BNCC em suas 63 escolas de Educação Básica, visando a atualização inicial dos currículos dos primeiros e segundos anos do Ensino Fundamental e, posteriormente, a atualização das demais etapas e níveis educacionais. Os professores, portanto, passaram novamente a se organizar para adequar os seus respectivos planos de trabalho, conforme sugere a BNCC, pouco tempo após uma reforma realizada, em 2013, com as DCN's. As representações sociais dos professores são essenciais para compreender o ponto de vista dos docentes sobre esta situação educacional atual e como ela influencia na sua profissão. Ademais, estas mudanças de realidades devem ser expostas aos acadêmicos graduandos em licenciatura para ficarem cientes das alteraçóes curriculares e se manterem sempre atualizados sobre as questôes que dizem respeito à educação em geral, isso inclui considerar e avaliar criticamente as implicaçôes e repercussóes nas realidades contemporâneas de cada contexto educacional.

O termo "representaçôes sociais" é extraído inicialmente da área da Sociologia com Durkheim por volta de 1897, passando por uma atualização e ressignificação para a área da Psicologia Social em 1961, através de Moscovici. Ao longo dos anos, 
a expressão passou por uma série de alteraçóes desde o seu conceito inicial, mas, segundo Pedra (1982), a sua definiçáo parte de uma expansão dos pensamentos objetivos e exatos para algo mais abstrato e particular. A ideia era trazer as interpretaçóes pessoais de cada indivíduo sobre determinados assuntos, podendo um mesmo tema ter inúmeros significados. Partindo por este pensamento, ele descreve:

Evidentemente existe, no caso das representaçôes, uma realidade material à qual importa referir-se, quando menos por ser aí seu local e espaço de ocorrência. Importa mais, todavia, referir-se a tal realidade enquanto realidade significada pelo sujeito ou por uma classe. O que se tem buscado é um enfoque significativo da representação social mesma, em vez de aterse a descrição das condiçôes materiais e objetivas nas quais os sujeitos ou as classes sociais elaboraram suas representaçóes. Assim, em vez de descrever, por exemplo, as práticas ideológicas do aparelho escolar, parece mais fundamental descobrir em que se transformam tais práticas e como são representadas ao se confrontarem com a realidade que pretendem negar (PEDRA, 1982, p. 68, grifos dos autores).

De uma forma mais simplificada, o autor considera que "[...] os sujeitos elaboram representaçóes distintas para objetos idênticos, de acordo com suas próprias e particulares condiçôes culturais e materiais de vida”. (PEDRA, 1982, p. 68). Dessa forma, podemos conceber que as representaçóes sociais são meios de compreensão que transcendem uma verdade absoluta, de modo a depender, fundamentalmente, da experiência do indivíduo sobre algo e como ele o interpreta, e, partir daí, o mundo se caracteriza como uma (re)apresentação das coisas e passa a guiar os pontos de vista de cada sujeito, que dáo significados às suas açóes nas relaçôes com os outros e com as coisas do mundo simbólico e cultural.

O objetivo desta pesquisa foi descrever e analisar as representaçóes sociais dos professores de Educaçáo Física, que atuam no ensino fundamental, da rede municipal de Gravataí/RS diante da BNCC. Para tal, o trabalho está organizado nas seguintes abordagens: a) a contextualização da Educação Física na BNCC; b) pesquisas mais recentes sobre o tema, a fim de constituir um parâmetro de diálogo com outras investigaçôes científicas. São, também, aqui descritos os principais procedimentos éticos e metodológicos adotados - incluindo as dificuldades e facilidades encontradas no decorrer da pesquisa - e, finalmente, os principais resultados e discussóes deste estudo.

O presente estudo possui grande relevância para o contexto atual da Educação Física escolar, pois as questóes discutidas neste artigo retratam o grau de receptividade por parte dos professores, e ajudam a elucidar as concepçóes trazidas por eles sobre o documento pedagógico normativo vigente, o que pode, consequentemente, contribuir na implementação da BNCC nas instituições de ensino.

\section{A EDUCAÇÃO FÍSICA NO CONTEXTO ESCOLAR}

O componente curricular da Educação Física ainda aparece na - até então - atual versão da LDB como obrigatório em toda a educação básica e deve ser 
configurado de acordo com a proposta pedagógica da escola, portanto é admitida a sua diversidade de abordagem, assim como ainda permanece mantida - a antiga e imaginada superada - a facultatividade de sua prática para alguns casos típicos de alunos (maiores de 30 anos, com jornada de trabalho superior a 6 horas diárias, serviço militar, ter prole ou algum problema de saúde). Desde 1996 este texto normativo vem sofrendo inúmeras alteraçôes à luz das disputas políticas do Congresso Nacional, portanto é sempre importante revisitar a versão atual diante desta disputa permanente de hegemonias e narrativas de verdades. A própria LDB prevê a necessidade da BNCC em todos os currículos da educação básica, a fim de atender as necessidades de aprendizagens da populaçáo brasileira, tanto nos seus aspectos nacionais, como também nas suas peculiaridades regionais e locais, através de complementaçóes legais dos estados e municípios. Nesta seção é apresentada, especificamente, como a Educação Física aparece no ensino fundamental e, como alguns estudos, têm interpretado esta realidade que repete, contraria e inova - ao mesmo tempo - o contexto educacional desta área de conhecimento.

\section{Base Nacional Comum Curricular e Educaçáo Física no Ensino Fundamental}

A Educação Física está presente na BNCC incorporada à área do conhecimento de Linguagens, juntamente com outros três componentes curriculares, sendo eles: Língua Portuguesa, Arte e Língua Inglesa. Consoante o documento, a Educação Física "[...] tematiza as práticas corporais em suas diversas formas de codificaçôes e significação social, entendidas como manifestaçôes das possibilidades expressivas dos sujeitos, produzidas por diversos grupos sociais no decorrer da história" (BNCC, 2017, p. 213). O Ensino Fundamental (se tratando da etapa educacional em questão para a elaboração do trabalho) é dividido em duas etapas, que são os Anos Iniciais, representado pelas turmas do $1^{\circ}$ ao $5^{\circ}$ ano e os Anos Finais, constituído pelas turmas do $6^{\circ}$ ao $9^{\circ}$ ano. A Educaçáo Física possui uma série de dez competências específicas a serem desenvolvidas, e passam a valer para todos os anos do Ensino Fundamental, que são:

1. Compreender a origem da cultura corporal de movimento e seus vínculos com a organização da vida coletiva e individual; 2. Planejar e empregar estratégias para resolver desafios e aumentar as possibilidades de aprendizagem das práticas corporais, além de se envolver no processo de ampliação do acervo cultural nesse campo; 3. Refletir, criticamente, sobre as relaçóes entre a realização das práticas corporais e os processos de saúde/doença, inclusive no contexto das atividades laborais; 4. Identificar a multiplicidade de padróes de desempenho, saúde, beleza e estética corporal, analisando, criticamente, os modelos disseminados na mídia e discutir posturas consumistas e preconceituosas; 5. Identificar as formas de produção dos preconceitos, compreender seus efeitos e combater posicionamentos discriminatórios em relação às práticas corporais e aos seus participantes; 6 . Interpretar e recriar os valores, os sentidos e os significados atribuídos às diferentes práticas corporais, bem como aos sujeitos que delas participam; 7. Reconhecer as práticas corporais como elementos constitutivos da identidade cultural dos povos e grupos; 8. Usufruir das práticas corporais de forma autônoma para potencializar o envolvimento em contextos de lazer, ampliar as redes 
de sociabilidade e a promoção da saúde; 9. Reconhecer o acesso às práticas corporais como direito do cidadáo, propondo e produzindo alternativas para sua realizaçáo no contexto comunitário; 10. Experimentar, desfrutar, apreciar e criar diferentes brincadeiras, jogos, danças, ginásticas, esportes, lutas e práticas corporais de aventura, valorizando o trabalho coletivo e o protagonismo (BNCC, 2017, p. 223).

Como forma de especificar os trabalhos a serem desenvolvidos nos componentes curriculares, cada um é composto por uma lista de Unidades Temáticas, Objetos de Conhecimento e Habilidades. Os Anos Iniciais possuem duas divisóes, a primeira que contempla do $1^{\circ}$ ao $2^{\circ}$ ano e a segunda que engloba do $3^{\circ}$ ao $5^{\circ}$ ano. Os Anos Finais possuem, igualmente, duas divisóes, a primeira que compreende do $6^{\circ}$ ao $7^{\circ}$ ano e a segunda que abarca do $8^{\circ}$ ao $9^{\circ}$ ano. As "Unidades Temáticas" são macro conteúdos culturais que são detalhados, mais especificamente, nos chamados "Objetos de Conhecimento" e expressos, respectivamente, em objetivos específicos tratados como "Habilidades". As Unidades Temáticas, então, dividem-se em seis, sendo elas: Brincadeiras e Jogos; Esportes; Ginásticas; Danças; Lutas; Práticas corporais de aventura. Convém mencionar que a Unidade Temática de lutas se faz presente, no modelo retratado pela BNCC, a partir do $3^{\circ}$ ano dos Anos Iniciais, e que as práticas corporais de aventura são retratadas apenas no início dos Anos Finais do Ensino Fundamental, a datar do $6^{\circ}$ ano. Apesar de apresentarem as mesmas Unidades Temáticas, os Objetos de Conhecimento e as Habilidades de cada macro conteúdo são responsáveis por diversificar e sistematizar os saberes a serem aprendidos de acordo com cada nível educacional.

\section{Revisão de Literatura}

Para a realização da revisão de literatura, foram consultados trabalhos publicados entre os anos de 2017 e 2019, sendo eles artigos, monografias, teses e dissertaçôes, presentes nas seguintes plataformas: Biblioteca Digital Brasileira de Teses e Dissertaçōes (BDTD), Scientific Electronic Library Online (SciELO) e Google Acadêmico. As palavras-chave utilizadas na busca dos estudos foram: "Educação Física Escolar"; "Representaçóes Sociais"; "BNCC"; "Professores". Os critérios adotados para a análise das pesquisas foram a aproximaçáo entre os conteúdos abordados, a relação entre as metodologias aplicadas e a presença fundamental do debate envolvendo a BNCC. Considerando as três plataformas, a procura resultou em dezenas de pesquisas, das quais a grande maioria acabou sendo descartada logo de início, por não atingirem os requisitos mínimos estabelecidos, enquanto 19 acabaram sendo analisadas de forma mais detalhada. Por último, três estudos se destacaram e foram selecionados para compor a presente pesquisa, pois esses corresponderam mais rigorosamente aos critérios mencionados acima.

O primeiro trabalho foi de Almeida (2018) que teve por objetivo a análise da Base Nacional Comum Curricular, tendo como foco a Educaçáo Física na etapa de Ensino Fundamental e suas implicaçóes no contexto social. Tendo caráter qualitativo, a pesquisa teve como métodos o estudo bibliográfico e a análise documental. Os resultados apontaram que a BNCC fez com que a Educaçáo Física retrocedesse no 
cenário educacional, indicando uma desvalorização das conquistas, em prol de uma educaçáo democrática, obtidas por professores e pesquisadores, evidenciada pela ausência de estímulos para uma ação autônoma de alunos e professores no processo de ensino-aprendizagem da disciplina em um ponto de vista crítico-cultural.

A segunda pesquisa, desenvolvido por Neira (2018), explorou o conflito entre a representação da Educação Física, presente na Base Nacional Comum Curricular, e a teorização escolar. A estratégia utilizada para a elaboração do artigo foi a de uma pesquisa documental, tendo essa uma natureza qualitativa. Os resultados indicaram um retorno de conceitos tecnocráticos, concretizados pelo privilégio do documento aos elementos técnicos, caracterizados por conceitos ultrapassados, incompatíveis e contraditórios à contemporaneidade, que acabam por fragilizá-lo. Além disso, a ausência de criticidade, revela, em definiçóes epistemológicas, a ausência de discussóes específicas da área e de seus respectivos problemas. Tal desconsideração ao olhar crítico e com um posicionamento omisso em relaçáo aos debates necessários, resultam em uma BNCC, segundo o autor, precária, incongruente e inconsistente.

O terceiro, e último, estudo desenvolvido por Assunçáo (2018) promoveu um debate sobre a Base Nacional Comum Curricular, juntamente com o reconhecimento de políticas públicas, centrado em aspectos da Geografia enquanto inserida na Pedagogia. Como método, Assunção formulou um questionário que foi destinado a dois professores e um formando de Pedagogia do município de Porto Alegre (tal roteiro do questionário foi usado, com adaptaçóes, aqui nesta presente pesquisa). Os resultados mostraram que os professores não tiveram nenhuma atualização para que pudessem se adequar às novas diretrizes, consequentemente, comprometendo a aplicabilidade do novo documento nas escolas e dando margem para um possível não seguimento das propostas da BNCC.

As pesquisas, mencionadas acima, serão retomadas ao longo do artigo, a fim de que se promova um diálogo entre os resultados levantados pelos autores citados e os dados obtidos na presente pesquisa, de modo a contribuir no debate atual e sempre permanente sobre as representaçóes da Educaçáo Física no cotidiano escolar.

\section{METODOLOGIA}

O presente trabalho se utilizou de uma abordagem com características quali-quantitativas, sendo essa uma combinação da pesquisa qualitativa que, para Appolinário (2011, p. 149) refere-se a uma "modalidade de pesquisa na qual os dados são coletados através de interaçóes sociais", com a pesquisa quantitativa que, conforme o autor, remete a uma "modalidade de pesquisa na qual variáveis predeterminadas sáo mensuradas e expressas numericamente." (p. 150). Minayo e Sanches (1993) apud Souza e Kerbauy (2017, p. 37) fazem o seguinte comentário acerca da utilização das duas estratégias no desenvolvimento de uma pesquisa:

A relação entre quantitativo e qualitativo, entre objetividade e subjetividade não se reduz a um continuum, ela não pode ser pensada como oposição contraditória. Pelo contrário, é de se desejar que as relaçôes sociais possam ser analisadas em seus aspectos mais "ecológicos" e "concretos" e aprofundadas 
em seus significados mais essenciais. Assim, o estudo quantitativo pode gerar questóes para serem aprofundadas qualitativamente, e vice-versa.

Além disso, o estudo partiu de uma amostragem não probabilística que, segundo Mattar (1996) apud Oliveira, (2001, não paginado) "é aquela em que a seleçáo dos elementos da população para compor a amostra depende ao menos em parte do julgamento do pesquisador ou do entrevistador no campo." O tipo de amostragem não probabilística escolhido foi o por conveniência, no qual, de acordo com Schiffman e Kanuk (2000) apud Oliveira (2001, não paginado), "o pesquisador seleciona membros da população mais acessíveis."

Antes da realização da pesquisa, foi utilizado o Mapa Georreferenciado de Gravataí, desenvolvido e disponibilizado pela Secretaria Municipal de Desenvolvimento Urbano (SMDUR), o qual serviu para identificar as 63 escolas da rede municipal e caracterizar a cidade em cinco regióes distritais, possibilitando a divisão das instituiçóes de ensino em seus respectivos distritos, sendo eles o Distrito Sede, considerado de zona urbana, e o Distrito do Barro Vermelho, o Distrito de Morungava, o Distrito do Itacolomi e o Distrito do Ipiranga, classificados como distritos de zona rural. A composição das referidas regiôes distritais pode ser contemplada na Figura 1, abaixo:

Figura 1 - Mapa Digital das Regiōes Distritais de Gravataí/RS

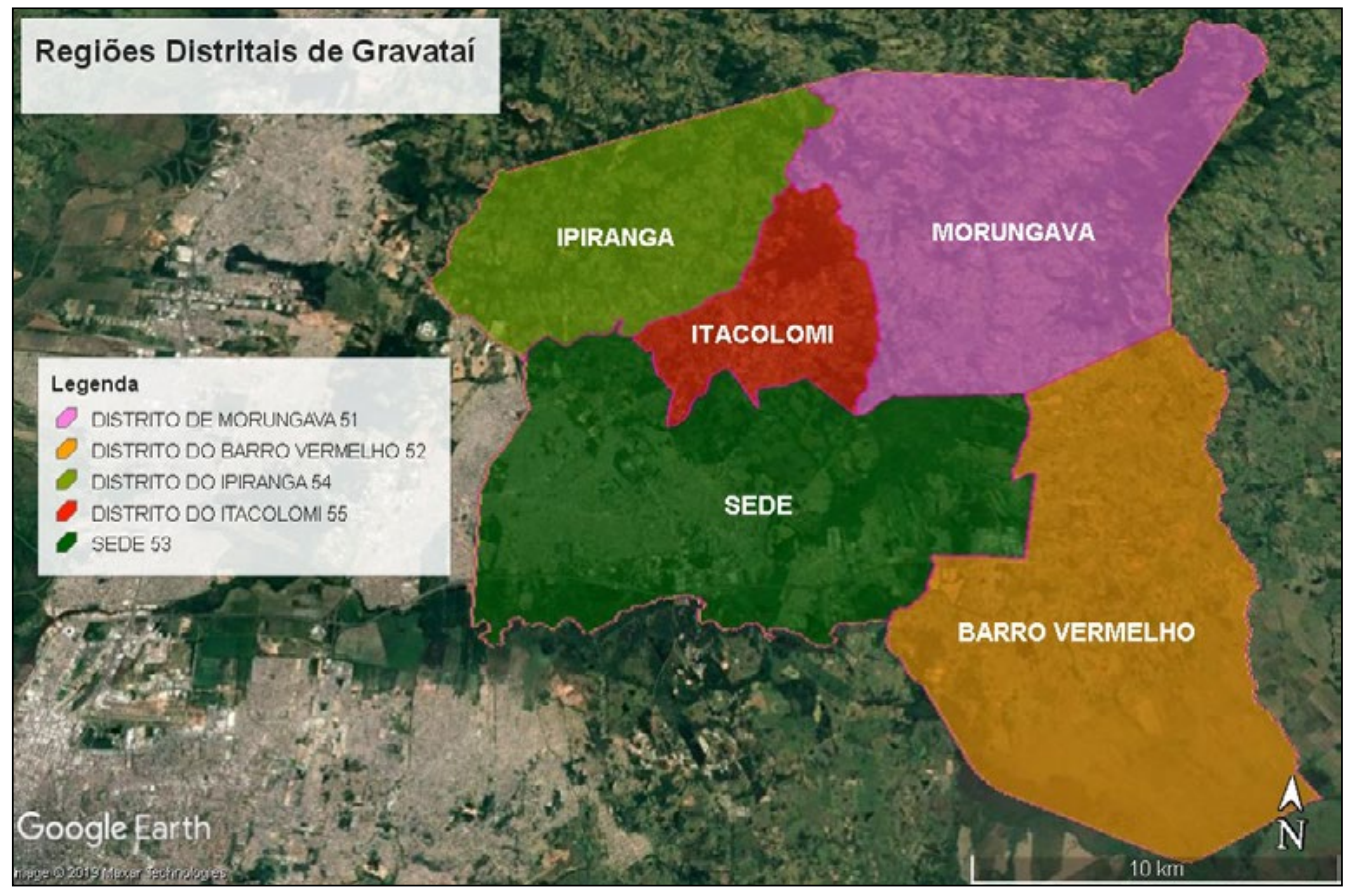

Fonte: SMDUR Gravataí/RS (2019, adaptada pelos autores). 
Após isso, foi solicitado - e, posteriormente, concedida - uma Carta de Anuência da Secretaria Municipal de Educação (SMED) de Gravataí/RS, autorizando o envio de um questionário eletrônico com questóes fechadas para as 39 escolas da rede municipal que possuíam profissionais de Educaçáo Física, e que seriam responsáveis por encaminhá-lo aos professores(as). Tal questionário teve por objetivo traçar um perfil profissional dos professores(as) e identificá-los por região, além de possibilitar um primeiro contato com os docentes. Diante da baixa obtençáo de retornos, os pesquisadores retornaram à SMED para saber se ela poderia, enquanto instituição local, remeter o questionário eletrônico às escolas, o que concordara. Além de solicitarem o envio por parte da SMED, simultaneamente, também enviaram o questionário através da técnica snowball, via WhatsApp, a fim de que ele chegasse a mais profissionais de forma organizada e mais rápida possível, orientando, assim, que esses repassassem o questionário a outros professores(as) que eles tivessem contato, de modo que estes procedessem da mesma maneira com outrem de seus convívios. De acordo com Baldin e Munhoz (2011, p. 332), a técnica snowball é:

[...] uma forma de amostra não probabilística utilizada em pesquisas sociais onde os participantes iniciais de um estudo indicam novos participantes que por sua vez indicam novos participantes e assim sucessivamente, até que seja alcançado o objetivo proposto [...].

As estratégias utilizadas, mencionadas anteriormente, fizeram com que o retorno fosse maior, mas, mesmo assim, acabou não sendo possível contemplar todas as regióes - com pelo menos um representante - do mapeamento das escolas do município. Deste modo, os pesquisadores retornaram novamente ${ }^{3}$ até a SMED para obterem os contatos das escolas das regióes que faltavam, a fim de que pudessem concluir esta etapa da pesquisa, solicitando diretamente a colaboraçáo dos supervisores, diretores e profissionais. Por fim, o questionário foi respondido por 13 professores da rede municipal, contemplando, assim, todas as regiôes distritais. Após o fechamento do questionário eletrônico, 10 participantes revelaram interesse em conceder uma entrevista, necessária para a continuação do estudo. Os quesitos antepostos para a definição dos colaboradores da próxima parte da pesquisa foram: disponibilidade, facilidade de contato, pluralidade nos aspectos de gênero/étnica/ idade e localização regional da escola.

A segunda parte da pesquisa contou com uma série de cinco entrevistas, sendo realizada uma com cada profissional, que representasse uma das cinco diferentes regiōes distritais. Tratou-se de uma entrevista semiestruturada, contendo dez perguntas sobre as experiências profissionais de cada um(a) e de suas respectivas representaçóes sociais sobre a BNCC. Os encontros foram realizados em diferentes

3 O motivo de ter havido tantos retornos à secretaria, se deu por conta das restriçôes administrativas impostas por ela, as quais nos impossibilitaram de obter meios de contato direto com os professores e de adquirir informaçóes relevantes para o desenvolvimento da pesquisa, como o número total de professores de Educação Física na rede municipal e suas respectivas características (sexo, idade etc.). 
locais, tais como sala de aula, biblioteca e sala dos professores. As entrevistas foram, sequencialmente, gravadas, transcritas e enviadas aos entrevistados, para que eles pudessem validá-las em suas devoluçóes. Antes da realizaçáo da entrevista, cada profissional havia assinado, antecipadamente, o Termo de Consentimento Livre e Esclarecido (TCLE), desenvolvido pelos autores.

Como formas de análises dos resultados, foram utilizadas as seguintes técnicas: a) "análise de conteúdo", para as 5 entrevistas semiestruturadas com os professores(as) que - voluntariamente se disponibilizaram - configurando assim, a base das interpretaçóes das informaçóes de cunho qualitativo, e b) "análises estatísticas descritivas e também inferenciais" para os 13 questionários eletrônicos respondidos inicialmente pelos professores(as), atribuindo-se assim, a base dos dados de natureza quantitativa. De acordo com Bardin (2011, p.48) a análise de conteúdo trata-se de:

um conjunto de técnicas de análise das comunicaçóes visando a obter, por procedimentos sistemáticos e objetivos de descrição do conteúdo das mensagens, indicadores (quantitativos ou não) que permitam a inferência de conhecimentos relativos às condiçóes de produção/recepção (variáveis inferidas) destas mensagens.

Consoante Morais (2002, p. 8), a estatística descritiva:

[...] pode ser considerada como um conjunto de técnicas analíticas utilizado para resumir o conjunto dos dados recolhidos numa dada investigação, que são organizados, geralmente, através de números, tabelas e gráficos. Pretende proporcionar relatórios que apresentem informaçōes sobre a tendência central e a dispersão dos dados. Para tal, deve-se evidenciar: valor mínimo, valor máximo, soma dos valores, contagens, média, moda, mediana, variância e desvio padrão.

No caso desta pesquisa, os dados quantitativos se caracterizaram como não paramétricos diante do resultado do teste de normalidade de Shapiro-Wilk que conferiu $\mathrm{p}=0,008$, portanto foi usado o teste estatístico qui-quadrado de Pearson para estabelecer tentativas de algumas análises de associaçóes de resultados.

Foram observados os cuidados éticos previstos na Resolução no 466/2012 (Brasil, 2012) que resguardam a dignidade e autonomia humana diante dos experimentos científicos e para tal fizemos uso do Termo de Consentimento Livre e Esclarecido - TCLE com os professores(as) que se disponibilizaram participar da pesquisa e da Carta de Anuência expressa pela Secretaria Municipal de Gravataí, como cuidados básicos e necessários para evitar que quaisquer procedimentos trouxessem prejuízos aos participantes do estudo.

\section{DISCUSSÓES DOS RESULTADOS}

Após a coleta de dados, os resultados foram separados em quatro categorias, que foram expressas com extratos das representaçôes sociais dos professores, sendo elas: "Perfil e formação de professores"; "A Base Nacional Comum Curricular"; "Os conteúdos"; "Necessidade de modificaçôes nas escolas". As categorias foram criadas 
a fim de possibilitar uma melhor compreensão das informaçóes e de promover uma discussão mais consistente e íntegra dos elementos abordados. Além da divisão das categorias, foram elaboradas tabelas que representam as respostas dos 13 professores participantes do questionário eletrônico, sendo que $10(77 \%)$ deles concordaram em participar da entrevista, mas apenas 5 foram selecionados para retratarem as realidades de suas escolas, de acordo com suas respectivas e diferentes regiōes. Através dos profissionais que responderam ao questionário eletrônico, a pesquisa conseguiu atingir o número de 13 escolas municipais das 63 escolas totais de Gravataí/RS. Entretanto, levando em consideração o número de 39 escolas que possuem professores de Educação Física, pois as escolas só dispóem de profissionais da área se contemplarem os Anos Finais do Ensino Fundamental, o índice atingido foi de $33 \%$ da totalidade válida das escolas que têm professores de Educaçáo Física. Segundo Markoni e Lakatos (2003), a média de retorno de questionários eletrônicos é de $25 \%$, portanto apesar de toda dificuldade encontrada e contornada pelos pesquisadores, o índice foi satisfatório para o desfecho da pesquisa, no entanto - como veremos adiante - não foi suficiente para permitir as análises inferenciais de associaçóes pretendidas.

\section{Perfil e formaçáo dos professores: “... eu me envolvi... peguei várias escolas”}

Tabela 1 - Perfil e formação dos professores de Educação Física

\begin{tabular}{|l|l|l|l|l|l|l|}
\hline $\begin{array}{l}\text { Profissionais } \\
\text { participantes }\end{array}$ & $\begin{array}{l}13 \text { pro- } \\
\text { fessores } \\
(100 \%)\end{array}$ & $\begin{array}{l}7(53,8 \%) \\
\text { mulheres }\end{array}$ & $\begin{array}{l}6(46,2 \%) \\
\text { homens }\end{array}$ & $\begin{array}{l}12(92,30 \%)^{4} \\
\text { com idades entre } \\
25 \text { e } 56 \text { anos }\end{array}$ & $\begin{array}{l}12 \\
(92,3 \%) \\
\text { brancos }\end{array}$ & $\begin{array}{l}1(7,7 \%) \\
\text { negros / } \\
\text { pardos }\end{array}$ \\
\hline $\begin{array}{l}\text { Instituiçáo } \\
\text { de formaçáo }\end{array}$ & $\begin{array}{l}4(30,7 \%) \\
\text { UFRGS }\end{array}$ & $\begin{array}{l}3(23,07 \%) \\
\text { ULBRA }\end{array}$ & $\begin{array}{l}1(7,69 \%) \\
\text { IPA }\end{array}$ & $1(7,69 \%)$ UFPel & $\begin{array}{l}1(7,69 \%) \\
\text { UNISI- } \\
\text { NOS }\end{array}$ & $\begin{array}{l}1 \\
(7,69 \%) \\
\text { PUCRS }\end{array}$ \\
\hline
\end{tabular}

Fonte: Elaborada pelos autores.

De acordo com o que é mostrado na Tabela 1, houve uma pluralidade de seis instituiçôes de formação dos professores, onde a Universidade Federal do Rio Grande do Sul (UFRGS) e a Universidade Luterana do Brasil (ULBRA) foram as principais. Existe, também, uma divisão proporcional entre o sexo masculino e feminino. Além disso, foi identificado uma diferença considerável entre as idades dos profissionais (média de 36,6 anos $\pm 10,6$ anos) e os tempos com que eles atuam na rede municipal de Gravataí/RS (média de 6,5 anos $\pm 8,5$ anos). Por outro lado, cabe ressaltar que a representação étnica entre os participantes foi de apenas $7,7 \%$

4 Um dos participantes $(7,7 \%)$ acabou não mencionando a idade durante o preenchimento do questionário.

52 participantes $(15,38 \%)$ não mencionaram a instituição de ensino que se graduaram, resultando em um número total menor do que era esperado. 
que se autodeclararam negros/pardos, enquanto a grande maioria se declarou branca, não havendo a representação de outras etnias que compóem o contexto étnico-racial brasileiro. Esta caracterização denota uma realidade de presença muito aquém de negros/pardos entre os professores de Educação Física de Gravataí/RS, tendo em vista que no estado do Rio Grande do Sul, segundo a Pesquisa Nacional por Amostra de Domicílio - PNAD (IBGE, 2018), o contingente de negros/pardos é de $21 \%$. A elaboração deste "perfil dos professores" teve o propósito de agregar informaçóes que resgatassem algumas das experiências e marcadores sociais destes sujeitos, a fim de poder melhor contextualizar as suas representaçóes sociais.

Para a segunda etapa da pesquisa, durante as entrevistas, houve a participação voluntária de três mulheres e dois homens, contando, entre os profissionais, com o único representante negro de todo o estudo. Entre os professores(as) entrevistados, manteve-se as diferentes instituições de ensino e as diferentes faixas etárias dos participantes, como já tinham sido evidenciadas pelos dados mostrados acima. A maioria dos professores entrevistados concluiu sua graduaçáo entre os anos de 2012 e 2016, enquanto outros concluíram o curso de Educação Física em décadas anteriores, sendo um em 1986 e outro em 2002.

Conforme as informaçóes obtidas durante as entrevistas, a grande maioria dos participantes disse possuir algum tipo de especialização, sendo que apenas o Professor 5 disse não possuir uma pós-graduação, mas que procurou se atualizar através de cursos online sobre conteúdos curriculares. Dentre as especializaçóes mencionadas pelos entrevistados, podemos citar a de Práticas de Ensino na Educação Física Escolar, a de Medicina do Esporte, a de Metodologia de Pesquisa em Educaçáo Física e a de Gestão Escolar. Uma curiosidade a respeito da pósgraduaçáo dos professores foi que o profissional mais jovem a conceder a entrevista, também era o profissional com o maior grau acadêmico entre os cinco, sendo o único com mestrado, do qual é focado na área de Comportamento Motor.

Além de trazerem os cursos realizados após concluírem a graduação, alguns participantes citaram projetos e atividades que desenvolveram durante o curso de Educação Física, como é o caso do Professor 1, o qual mencionou:

[...] no momento da graduaçáo, eu me envolvi com vários outros projetos, me envolvi com projetos de dança de saláo, projetos de ginástica para idosos, depois teve o PIBID de iniciaçáo à docência, a gente pegou várias escolas, aí, posteriormente, eu fui mais para o ramo da pesquisa [...]. (transcrição da entrevista do Professor 1, grifos dos pesquisadores)

Assim como o Professor 1, a Professora 3 também resolveu contar um pouco sobre a sua trajetória acadêmica, citando informaçôes interessantes sobre realizaçôes pessoais e projetos desenvolvidos na sua respectiva instituição de ensino, como segue na passagem abaixo:

Eu fui monitora de atletismo, fui monitora de judô com o professor X e fiz o curso de árbitro, um cursinho a mais bem no semestre que eu estava fazendo a disciplina, aí eu fui fazer as horas que tinham e, hoje eu sou árbitra nível 1, eu 
fui para a Olimpíada do Rio, então tem essas coisas boas assim. (transcrição da entrevista da Professora 3, grifos dos pesquisadores)

A manifestação desta professora deixa expressa "essas coisas boas" que podem decorrer dos envolvimentos que alguns profissionais de Educação Física têm com as práticas corporais, constituindo assim suas trajetórias de experiências formativas que os atribuem singularidades e distinçôes de oportunidades na carreira profissional. Esse aspecto é de suma importância para dinamizar as competências a serem desenvolvidas, segundo a BNCC.

O tópico sobre o perfil e formação dos professores possibilita a percepção acerca de uma parcela do quadro de professores de Educação Física, que atuam na rede municipal de Gravataí/RS. Tal item é fundamental para identificar as características dos docentes, promover relações entre informaçóes levantadas e contextualizar o estudo. Assunção (2018), em sua pesquisa, partiu do mesmo princípio ao aplicar um questionário, com o intuito de propiciar uma relaçáo entre o conteúdo teórico do trabalho e a prática na formação e ensino pedagógico.

\section{A Base Nacional Comum Curricular: "adaptar, adaptar, adaptar...”}

Tabela 2 - A BNCC na realidade dos professores

\begin{tabular}{|c|l|l|}
\hline $\begin{array}{c}\text { Possuem conhecimento so- } \\
\text { bre a BNCC }\end{array}$ & $13(100 \%) \operatorname{Sim}$ & $0(0 \%)$ Não \\
\hline Utilizam o documento & $11(84,6 \%) \operatorname{Sim}$ & $2(15,4 \%)$ Não \\
\hline Utilizam outras diretrizes & $7(53,8 \%) \operatorname{Sim}$ & $6(46,2 \%)$ Não \\
\hline
\end{tabular}

Fonte: Elaborada pelos autores.

Como exposto na tabela acima, os dados mostram que os professores, em sua totalidade, dizem possuírem conhecimento sobre a BNCC, e a grande maioria utiliza o documento como suporte no planejamento de suas aulas. Além disso, um número considerável de profissionais admitiu utilizar outras diretrizes curriculares. Entre os documentos mais citados pelos participantes do questionário, estão: os Parâmetros Curriculares Nacionais $(57,14 \%)$, as Diretrizes Curriculares Nacionais (14,28\%) e o Referencial Curricular Gaúcho - RCG (14,28\%). Esses dados de realidade nos mostram que as orientaçóes normativas mais recentes não apresentam a mesma apropriação e/ou utilização que a normativa antiga e vigente dos últimos 23 anos, que eram os PCN's. Com isso, um alerta para melhor estudarmos e entendermos o tempo necessário que uma legislaçáo é aprovada e, de fato, é acessada, apropriada e executada nos contextos culturais diversos. Estudos de Costa e Pereira Filho (2016), apontaram que o esporte é a cultura corporal de movimento considerada mais importante e mais desenvolvida nas aulas de Educação Física, em Campo Bom/RS. Em contrapartida, as lutas e as danças são consideradas as menos importantes e, praticamente, não são desenvolvidas enquanto conteúdo das aulas, a despeito das orientaçóes dos PCN's . 
Outra questáo indagava sobre a opiniáo dos professores em relação a BNCC e suas próprias organizaçôes e sistematizaçóes dos conteúdos curriculares, os quais, com o índice de 76,9\%, consideram o documento positivo, pois acreditam que ele facilita o processo em questão; $15,4 \%$ dos profissionais creem que a BNCC seja negativa, porque acreditam que ela dificulta esse procedimento; já 7,7\% dizem se sentir indiferentes sobre uma possível positividade ou negatividade do documento, pois declaram que ele não influencia nos seus métodos de organização e sistematização dos conteúdos curriculares.

Apesar de $100 \%$ dos participantes, quando perguntados no questionário eletrônico, dizerem possuir conhecimento sobre a BNCC, alguns, durante a entrevista, expressaram não possuírem uma compreensão profunda dela. Os professores 1 e 5 deram ênfase nas habilidades e competências especificadas no documento, indo contra ao que é mencionado por Neira (2018), sobre os aspectos técnicos do documento, quando ele diz que "[...] um currículo baseado em competências e habilidades prescritas reduz as possibilidades pedagógicas do professor [...]" (NEIRA, 2018, p. 222). D e acordo com os professores 1 e 5, esses componentes são considerados como norteadores, melhorando a objetividade das abordagens, as quais eram desenvolvidas anteriormente de maneira mais aleatória, e que, agora, náo possuem, necessariamente, um carácter técnico, mas, sim, facilitador. O professor 1, inclusive, declara sobre a associação do que já era desenvolvido por ele nos PCN's com esses dois novos elementos trazidos pela BNNC, no seguinte fragmento da entrevista:

Agora eu especifico em cada esporte qual habilidade, qual competência eu vou trabalhar, então, da BNCC, foi o que eu coloquei a mais em relação ao que eu trabalhava com os PCNs, antes eu trabalhava de uma forma mais geral, agora eu trabalho de uma forma mais específica. (transcrição da entrevista do Professor 1)

O que chamou atenção durante a entrevista, é que alguns profissionais disseram que foram orientados pela SMED a estudar a BNCC, bem como o RCG e um documento de nível municipal, a fim de montar estratégias de ensino para contemplar um documento padrão que seria incorporado por todas as escolas. A Professora 3, por exemplo, salientou a repetição das ideias, apesar de estarem em documentos diferentes e fez um comentário sobre as nomenclaturas adotadas na BNCC que, segundo ela, são apenas títulos novos para conceitos antigos. Por outro lado, outros professores náo mencionaram tal orientaçáo e nem a incorporação de outras fontes além da BNCC, o que nos leva a crer que a estratégia de gestão pública utilizada pela SMED para desencadear o planejamento de ensino em consonância com a BNCC náo contemplou todas as escolas - ou, pelo menos, todos os professores - da rede municipal de Gravataí/RS.

Em relação a importância, atribuída pelos entrevistados, sobre o documento, pode-se mencionar a intenção da padronização dos conteúdos e, consequentemente, do ensino, independentemente da escola e de sua natureza pública ou privada; a promoção de uma aprendizagem igualitária aos alunos; e a possibilidade de orientar 
o professor, a fim de ajudá-lo a se organizar durante o desenvolvimento dos planos de aula em geral.

$\mathrm{O}$ acesso ao documento ocorreu de diferentes maneiras. Alguns professores mencionaram ter participado de reunióes, em suas respectivas escolas, para tratar de assuntos específicos sobre a BNCC e sua implantação nas escolas da rede municipal. A maioria dos profissionais que disseram ter participado dessas reunióes, também disseram que elas acabaram sendo superficiais ou que não dedicaram uma importância devida ao tema, o que acabou resultando na substituição do assunto por exigências, por parte dos professores, de melhores condiçôes em relação às estruturas materiais e físicas da escola, como relata a Professora 3. Os entrevistados que não expressaram ter participado das reunióes, contaram ter acesso de outras maneiras, como, por exemplo: o Professor 4, que recebeu o documento através de um e-mail enviado pela supervisão da escola; a Professora 3, que teve acesso, de fato, em outro município e que acabou participando de uma reunião, similar às mencionadas acima, que não atingiram as expectativas dos professores; e a Professora 5 , que buscou o acesso por conta própria, após a solicitação por parte da SMED para a composição das estratégias de ensino em nível municipal.

Dentre os pontos positivos trazidos pelos entrevistados, há, de forma geral, o que já havia sido trazido por eles em relação a importância da BNCC, como, por exemplo, a padronização do ensino, a adiçấo de elementos específicos das habilidades e competências abordadas, além de uma melhor organização e orientação para os docentes. Além dessas questóes, a Professora 3 destaca a atualização dos profissionais em geral, como é exposto no trecho abaixo:

[...] ela vai ajudar, principalmente para quem está iniciando e para os velhos também, porque estão tão acostumados naquele mesmo caminho, naquela mesma coisa... e todo mundo vai ter que se adaptar, todo mundo vai ter que correr atrás de coisas diferentes. Para aquele que está sempre dando a mesma coisa, ele vai ter que mudar. Para aqueles que estão iniciando, que estâo meio perdidos, porque por mais que tu tenha estudado como fazer um planejamento, como fazer tudo, não é a mesma coisa no dia-a-dia. (transcriçáo da entrevista da Professora 3)

Sobre os pontos negativos, a Professora 3 e o Professor 4 disseram não haver, pois, de acordo com a primeira, a BNCC precisa ser colocada em prática antes para que possa ser feita uma análise mais precisa dela, apesar de parecer que os responsáveis por ela não possuem qualquer noção sobre a realidade das escolas brasileiras, enquanto o outro diz que o documento trata apenas de orientar os profissionais, que não é uma questão de obrigação trabalhar determinados conteúdos e que, por isso, náo pode ser considerado como um ponto negativo. A Professora 2 e a Professora 5 manifestaram pontos negativos na ausência de uma maior divisáo entre os anos escolares que, para elas, o fato de repetir os conteúdos ou de englobar mais de um ano em um contexto semelhante, pode gerar certas indecisôes por parte do professor na hora de desenvolver o seu plano de aula. Para o Professor 1, o documento é considerado, em partes, utópico, pois algumas orientaçôes acabam 
fugindo do domínio do próprio profissional, e acabam sendo barradas, muitas vezes, pela própria realidade da escola, como ele enfatiza no seguinte excerto da entrevista:

Tu olha, tu lê, tu acha lindo, mas aí, na hora da prática... não é porque tu não quer, é que é sempre essa relação de adaptar, adaptar, adaptar... porque cada um tem a sua realidade, então ali eles escrevem de uma forma mais geral, padronizando e tudo mais, te orientando, te dando mais segurança, mas quando tu vai lá para a prática eles não estão junto contigo pra dizer que é assim ou assado, não, é contigo, te vira! (transcrição da entrevista do Professor 1 , grifos dos pesquisadores)

\section{Os conteúdos: "tive uma escola que era só futebol"}

Tabela 3 - Unidades temáticas mais trabalhadas

\begin{tabular}{|l|l|l|l|l|l|l|}
\hline $\begin{array}{l}\text { Unidades } \\
\text { temáticas }\end{array}$ & $\begin{array}{l}13(100 \%) \\
\text { Esportes }\end{array}$ & $\begin{array}{l}13(100 \%) \\
\begin{array}{l}\text { Jogos e } \\
\text { brincadeiras }\end{array}\end{array}$ & $\begin{array}{l}12(92,3 \%) \\
\text { Ginástica }\end{array}$ & $\begin{array}{l}7(53,8 \%) \\
\text { Lutas }\end{array}$ & $\begin{array}{l}6(46,2 \%) \\
\text { Danças }\end{array}$ & $\begin{array}{l}5(38,5 \%) \\
\text { Práticas } \\
\text { corporais } \\
\text { de aventura }\end{array}$ \\
\hline
\end{tabular}

Fonte: Elaborada pelos autores.

A Tabela 3 revela que as unidades temáticas mais desenvolvidas pelos professores(as), sendo unanimidade entre eles, os esportes e os jogos e brincadeiras. Mostra, também, que as lutas, as danças e as práticas corporais de aventura são as unidades menos realizadas entre todas, sendo que as duas últimas citadas são desempenhadas por menos da metade dos profissionais. Outrossim, relacionando com os dados da Tabela 1 , as informaçóes levantadas para compor a Tabela 3 apontam que, dentre as 7 participantes femininas, todas elas trabalham com a ginástica, enquanto apenas $42,5 \%$ se valem das lutas, das danças e das práticas corporais de aventura. Enquanto, dentre os 6 participantes masculinos, $83 \%$ deles executam ginástica, $67 \%$ aplicam lutas, $50 \%$ desenvolvem danças e somente $33 \%$ trabalham as práticas corporais de aventura. Esses dados revelam que as professoras mulheres atuam mais com as ginásticas e, em contrapartida, os homens estáo mais presentes nas lutas e, curiosamente, nas danças. Este resultado suscita a importância de novos estudos para analisar a possível associação do sexo do(a) professor(a) na abordagem das práticas corporais, pois é sabido que nos primórdios da formação profissional da Educação Física no Brasil - em especial o Decreto-lei no 1212/1939, que criou a Escola Nacional de Educaçáo Física e Desportos (ENEFD), segundo Brasil (1939) - o caráter sexista era marcante. Pereira Filho (2000), em seus estudos, apresenta farta abordagem sobre esta temática. Nesta presente pesquisa não foi possível, no teste quiquadrado de Pearson, identificar nível de associaçáo significativa, pois na variável dependente "práticas corporais" a contagem esperada deu abaixo de 5 (com exceção dos esportes e ginásticas) e os resíduos ajustados apontaram baixa associação (fora dos +3 ou -3), desta forma o número de 13 participantes não foi suficiente para estabelecer as análises inferenciais desejadas, sendo assim, a ampliação deste número 
de professores(as), em outras pesquisas, podem possibilitar tal análise e qualificar as interpretaçốes sobre esta realidade.

Tratando-se das regiôes distritais de Gravataí/RS (Figura 1), três delas contemplam todas as seis unidades temáticas previstas pela BNCC, sendo elas: Sede, Distrito de Morungava e Distrito do Itacolomi. Entretanto, o Distrito do Ipiranga e o Distrito do Barro Vermelho são regióes, segundo os dados levantados, onde as unidades de danças, lutas e práticas corporais de aventura não são desenvolvidas, limitando-se, apenas, aos esportes, as ginásticas e os jogos e brincadeiras.

Os conteúdos - de esportes, jogos e ginásticas - privilegiados pelos entrevistados se assemelham muito, tendo destaque para o futsal, o futebol, o handebol, o vôlei, o atletismo, o basquete, os jogos, as brincadeiras e as ginásticas que são aludidos por, praticamente, todos os professores. Dentre os conteúdos menos citados, podemos indicar o jogo de botáo, o ping pong, as danças e as lutas, em especial a capoeira, trabalhada apenas pela Professora 2. Os professores disseram escolher os conteúdos através de critérios pessoais, mas boa parte deles expressaram trabalhálos, de acordo com níveis de complexidade, do mais fácil para o mais difícil. Além disso, os profissionais consideram os conteúdos previstos na BNCC para selecionar os que irão compor as suas aulas, sendo que, grande parte deles, tem o objetivo de apresentar diferentes conteúdos para que os alunos náo fiquem imersos apenas no futebol/futsal, e tenham uma gama maior de vivências corporais. No meio da entrevista, a Professora 3 relata sobre um momento que ficou surpresa por conta de os alunos quererem praticar outra modalidade esportiva, no caso o handebol, no lugar do futebol.

Eu tive uma escola que era só futebol e a gente foi gradativamente, até que um dia eu disse que eles podiam escolher, que eles podiam jogar, já tinha separado a bola de futebol, mas aí eles se olharam, e isso era com o $9^{\circ}$ ano, e eles decidiram jogar handebol. Aí me perguntaram se eu estava passando mal e eu disse que sim, porque dentro das opçóes eles escolheram o handebol. (transcrição da entrevista da professora 3, grifos dos pesquisadores).

Esta realidade relatada é problematizadora, pois, apesar de diversificar, internamente, a cultura corporal do esporte, continua restrita à mesma, porque tanto o futebol quanto o handebol estão imersos na Unidade Temática dos Esportes, que aparecem na realidade de Gravataí, como abordada por todos os professores. A surpresa da docente fica por conta do futebol ser, praticamente, a exclusividade cultural dos esportes nas escolas, onde pensar em outra prática corporal pode ser motivo de suspeita que o(a) professor(a) possa estar "passando mal" diante do inusitado. Neste aspecto, a BNCC obriga que este "inusitado" seja uma nova realidade recorrente, e algumas dificuldades apareçam nas comunidades escolares, desta forma, novas representações sociais poderão ser constituídas com a implementaçáo da BNCC.

Quando perguntados sobre as maiores dificuldades encontradas na aplicação de algum conteúdo específico, os entrevistados trouxeram diferentes situaçốes, mas nada sobre o conteúdo propriamente dito, com exceção do Professor 4, que 
contou ter desenvolvido um conteúdo de dança e esse ter dado errado pela falta de domínio do próprio em relação ao tema e pela ausência de interesse por parte dos alunos masculinos, resultando na exclusão da unidade da dança pelo docente. As dificuldades levantadas pelos profissionais partem de fatores sociais, como no caso do Professor 1, que sente grande dificuldade em trabalhar com alunos de inclusão; a Professora 2 diz ter o desafio de mudar a concepção dos alunos sobre a Educaçáo Física, pois eles acabaram tendo uma ideia errada sobre o componente, por conta do tratamento dado pelos profissionais responsáveis pelos Anos Iniciais, e isso acaba atrapalhando o desenvolvimento de suas aulas; a Professora 3 diz que muitos conteúdos são afetados pela falta de estrutura física da escola, gerando reclamaçóes por parte dos responsáveis dos alunos, por conta dos riscos de lesóes, e, até mesmo, dos profissionais que atuam na escola, que se incomodam com o barulho gerado pelas crianças; o Professor 4, além da dança, diz que a entrada de alunos novos, já nos Anos Finais do Ensino Fundamental, atrapalha no processo das aulas, porque ele acaba não tendo o conhecimento das experiências corporais que os alunos tiveram anteriormente; a Professora 5, assim como a Professora 3, alegou que a ausência de uma boa estrutura física na escola, compromete no desenvolvimento das aulas, pois grande parte delas demanda de um espaço apropriado, o qual, caso fosse ofertado, facilitaria para uma maior qualidade referente à realizaçáo das atividades. Sobre os conteúdos que possuem maior êxito entre os entrevistados, podem-se citar o atletismo, vôlei, futebol, handebol e atividades com música, sendo esses, basicamente, os principais conteúdos desenvolvidos por eles, como visto anteriormente.

A maioria dos professores entrevistados já atuava nas escolas antes da BNCC ter sido homologada, e os próprios disseram trabalhar certos conteúdos que, mesmo tendo sido desenvolvidos precedentemente, se encaixam em cinco das seis unidades temáticas presentes no atual documento, com exclusão das práticas corporais de aventura. Os professores que passaram a atuar com a BNCC já em vigor, informaram possuir dois objetivos com relação aos conteúdos durante a graduação: trabalhar com atividades que já tinha familiaridade, no caso do Professor 1 a respeito da dança, e trabalhar com atividades que nunca tinha experimentado enquanto aluno (de $1^{\circ} \mathrm{e}$ $2^{\circ} \mathrm{grau}$ ), a fim de promovê-las enquanto educadora, como declara a Professora 2:

Eu sempre pensava em esportes diferentes como o atletismo, pois sempre temos o futebol $\mathrm{e}$, às vezes, o vôlei, mas existem tantos outros que não são vistos, então chegam esses esportes de marca e precisão que entra o atletismo, alguns outros, a parte de ginástica, de lutas... tem tantas coisas que eu pensava, enquanto estudante, sobre o motivo de não ter tido aula de determinado conteúdo e depois aparecem ali, como os jogos cooperativos. (transcrição da entrevista da Professora 2)

Após serem questionados sobre o que seria considerado inviável, nos seus respectivos ambientes de trabalho, sobre algo previsto na BNCC, os entrevistados se dividiram. O Professor 1 enunciou que a aplicação integral dos elementos previstos no documento é algo inviável, assim como certas modalidades do atletismo e da ginástica por falta de materiais; a Professora 2 proferiu que tudo é possível de ser 
realizado, mesmo que, às vezes, seja de uma forma adaptada por conta da estrutura e/ou dos alunos de inclusão; a Professora 3, além de compartilhar da mesma opinião do Professor 1 sobre as ginásticas, também se mostrou preocupada em relação aos jogos eletrônicos, pois eles acabam não podendo ser desenvolvidos em consequência da falta de recursos da escola; o Professor 4 disse acreditar na existência de um elemento inviável, mas não conseguiu recordar de algo específico; já a Professora 5 mencionou que as práticas corporais de aventura se tornam inviáveis na sua realidade, pois a escola em que ela trabalha náo dispóe de uma área adequada para a execução de atividades relacionadas a essa unidade.

Em relação aos conteúdos contidos na BNCC e trabalhados pelos professores de Gravataí/RS, nota-se que não há uma preocupaçáo, nem sequer uma mençáo sobre uma possível conjuntura que possa ferir a autonomia dos docentes por conta do novo documento, como é evidenciado no trabalho de Almeida (2018) ou, mais vigorosamente, no estudo de Neira (2018), quando o autor menciona que "o documento homologado volta-se para a conformação e aceitação de um desenho social injusto, num momento histórico em que os professores deveriam ser apoiados na elaboração de currículos democráticos e democratizantes". (NEIRA, 2018, 222). Ao contrário do que os autores dizem, os professores parecem confortáveis com as indicaçôes presentes na BNCC, e tratam as Unidades Temáticas e seus derivados como recomendaçóes básicas de trabalho, não abordando rigorosamente todos os elementos inclusos no documento, mas sim de acordo com critérios pessoais e condicionais.

\section{Necessidade de modificaçóes nas escolas: “... passar aos alunos o entendimento da Educaçáo Física como disciplina como qualquer outra”}

Tabela 4 - Tempo de atuação dos professores na rede municipal

\begin{tabular}{|l|l|l|l|l|}
\hline $\begin{array}{l}\text { Tempo de } \\
\text { atuaçáo } \\
\text { nas escolas } \\
\text { municipais }\end{array}$ & $\begin{array}{l}13(100 \%) \text { estáo } \\
\text { entre } 6 \text { meses e } \\
28 \text { anos }\end{array}$ & $\begin{array}{l}9(69,2 \%) \text { de } 0 \text { a } \\
5 \text { anos }\end{array}$ & $\begin{array}{l}1(7,7 \%) \text { de } 6 \text { a } \\
10 \text { anos }\end{array}$ & $\begin{array}{l}3(23,1 \%) 11 \\
\text { anos ou mais }\end{array}$ \\
\hline
\end{tabular}

Fonte: Elaborada pelos autores.

A Tabela 4 evidencia uma diversidade em relação ao tempo que os professores estáo atuando nas escolas da rede municipal de Gravataí/RS, apesar da maior parte estar atuando há pouco tempo, atestando uma recente renovação dos profissionais da área de Educação Física. Os participantes citaram trabalhar em 13 escolas, das quais a grande maioria pertence a Sede, sendo 9 no total, enquanto os outros distritos compreendem uma escola cada. A diferença na quantidade de escolas, entre as regióes distritais de Gravataí, se dá pela categoria que ela está inserida, sendo a Sede considerada como um distrito de zona urbana, e os outros quatro distritos classificados como de zona rural. 
Quando perguntados sobre o que precisaria ser modificado em suas respectivas escolas para que as aulas de Educação Física se aproximassem ao que está previsto na BNCC, a grande maioria dos professores respondeu que a ausência de uma boa estrutura física e material acaba prejudicando e comprometendo a aplicaçáo de uma série de conteúdos e, consequentemente, de atividades. Como efeito, os professores acabam tendo que criar alternativas para que as aulas sejam aplicadas, sendo que, como dito pelo Professor 1, "[...] às vezes tu deixa de trabalhar o conteúdo que tu estava trabalhando, de acordo com a BNCC, para estar dentro da sala de aula fazendo alguma outra brincadeira completamente diferente daquilo que tu propôs antes" (transcrição da entrevista do Professor 1). A falta de uma estrutura adequada parece ser um problema recorrente nas escolas da rede municipal de Gravataí/RS, mas, além disso, outras adversidades têm surgido e preocupado os profissionais.

Algumas dificuldades foram expostas de maneira exclusiva por parte dos professores, como, por exemplo, o distanciamento entre a Educaçáo Física e a Pedagogia, como mencionado pela Professora 2, o qual diz que as pedagogas poderiam "[...] se integrar mais da Educaçáo Física, de passar aos alunos o entendimento da Educação Física como disciplina como qualquer outra, para eles respeitarem mais e terem essa compreensão" (transcrição da entrevista da Professora 2, grifos dos pesquisadores). Segundo a Professora 2, o profissional de Educaçáo Física acaba sendo prejudicado pelo descaso por parte das pedagogas com o referido componente curricular na primeira etapa do Ensino Fundamental. Esta abordagem remete a importância de outras pesquisas sobre a Educação Física na Educação Infantil e nos anos iniciais, pois retoma um tema muito discutido, historicamente, e que já se constituiu numa bandeira de luta e reinvindicação da categoria profissional que é obrigatoriedade da presença dos profissionais da Educação Física nestes níveis de educação. Aqui não será discutida esta abordagem, mas fica o alerta para não a restringir ao âmbito corporativo e sobre a necessidade de maiores estudos referentes à interdisciplinaridade que está imersa na BNCC da educação infantil e dos anos iniciais, onde desafia o diálogo - e não o embate - entre a Educação Física e a Pedagogia.

Outra reivindicação específica parte pelo Professor 1, o qual enfrenta complicaçóes quando se trata de conteúdos teóricos, por conta de um problema de aprendizagem geral dos alunos. Segundo ele, "[...] os alunos chegam, às vezes, no $6^{\circ}$ ano sem saber ler direito [...]" (transcrição da entrevista do Professor 1), o que acaba frustrando os planos do professor em aplicar determinados conteúdos. O mesmo professor sugere que os profissionais tenham uma espécie de formação continuada para lidar com situaçóes adversas, seja pela falta de estrutura da escola e a consequente necessidade de adaptação das atividades ou pela falta de domínio por parte do profissional, de algum elemento presente dentro das Unidades Temáticas. Com uma proposta semelhante, o Professor 4 diz que, para um desenvolvimento integral, na sua respectiva escola, dos conteúdos contidos na BNCC, seria fundamental uma formaçáo dele próprio na unidade de Dança, ou, se fosse o caso, na parceria com voluntários da comunidade, que tivessem domínio da área e que estivessem dispostos a trabalhá-la com seus alunos em sua escola. Outra sugestão 
do Professor 4, para uma possível aproximaçáo do modelo previsto na BNCC à sua realidade, está na contribuição de estudantes do curso de Educação Física como estagiários, que, segundo ele, agregaria muito no desenvolvimento pleno das aulas.

Os resultados mostram que, apesar de serem componentes distintos e de haver uma especificidade da Educação Física nos aspectos de espaço físico e material, os problemas de formação e atualização dos professores, apresentados no trabalho de Assunção (2018), acabam se repetindo na presente pesquisa. Além disso, as informaçôes obtidas na pesquisa se consubstanciam num problema histórico da educação brasileira: qualquer alteração curricular exige políticas públicas consistentes, continuadas e sistemáticas.

\section{CONCLUSÁO}

As representações sociais dos professores de Educação Física, da rede municipal de Gravataí/RS, revelaram importantes elementos acerca desta etapa inicial de implementação da BNCC na prática docente. Pode-se considerar, partir das concepçôes dos professores, que a ausência de uma boa estrutura física e material, e a falta de domínio em certos conteúdos, são os principais fatores que dificultam a implementação do modelo previsto no documento. No entanto, eles consideram que a padronização do ensino e a adição de elementos específicos das habilidades e competências abordadas são aspectos importantes contidos na BNCC, além de acreditarem que o documento os auxilia a terem uma melhor organização e orientação.

A BNCC é um documento recente e os profissionais da área da educação ainda estão em processo de adaptaçáo e assimilação às novas diretrizes apresentadas. Assim como é mostrado no estudo de Assunção (2018), nessa pesquisa, boa parte dos professores não receberam a devida orientação e atualização para que se adequassem à nova proposta. Apesar de ser um documento de extrema importância, a BNCC acaba náo tendo a expressividade necessária para uma adesão integral por parte das escolas municipais de Gravataí/RS, sendo que, de acordo com os docentes que a utilizam, eles fazem isso de maneira parcial, seja por limitaçóes de estrutura física, de condiçóes materiais, de hábitos culturais dos alunos e/ou de conhecimento específico do próprio professor.

O estudo foi importante para mostrar o impacto da implementação do novo documento normativo na prática dos professores de Educação Física da rede municipal de Gravataí/RS, além de expor suas respectivas facilidades, dificuldades, satisfações e contrariedades a respeito da BNCC. A pesquisa pode servir como base para a realizaçáo de novos trabalhos - inclusive foram sinalizados ao longo do texto - com temas que visam investigar e aprofundar sobre a relaçáo entre a prática docente, a aplicabilidade das diretrizes curriculares atuais e as suas diferentes representaçóes sociais.

Cabe ressaltar que os estados e municípios estão em um processo de efetivação de seus referenciais curriculares, o que significa que os elementos contidos na 
BNCC podem passar por modificaçóes e adaptaçóes para atenderem melhor as especificidades das respectivas realidades, no contexto educacional, apresentadas por um determinado local.

\section{REFERÊNCIAS}

ALMEIDA, Déberson Ferreira de. Base Nacional Comum Curricular: concepção do componente Educação Física para o Ensino Fundamental. Dissertaçáo de Mestrado em Educação - Programa de Estudos Pós-Graduados em Educação, Pontifícia Universidade Católica de São Paulo, São Paulo, 2018. Disponível em: <http://bdtd.ibict.br/vufind/ Record/PUC_SP-1_517a3abc342283cfcf40d2465e022519>. Acesso em 18 abr. 2019.

APPOLINÁRIO, Fábio. Dicionário de metodologia científica: um guia a produção do conhecimento científico. 2. ed. São Paulo: Atlas, 2011. 1 recurso online ISBN 9788522466153.

ASSUNÇÃO, Francielle Rodrigues. Os Es-Passos da geografia na BNCC: uma análise do $1^{\circ}$ ao $6^{\circ}$ ano. Trabalho de conclusão de graduação em pedagogia - Faculdade de Educação, Universidade Federal do Rio Grande do Sul, Porto Alegre, 2018. Disponível em: <https://www.lume.ufrgs.br/handle/10183/183663?show=full >. Acesso em 18 abr. 2019.

BALDIN, Nelma e MUNHOZ, Elzira M. Bagatin. Snowball (Bola de Neve): uma técnica metodológica para pesquisa em educaçáo ambiental comunitária. X Congresso Nacional de Educação - EDUCERE. Anais Eletrônicos. Pontifícia Universidade Católica do Paraná, Curitiba, 7 - 10 nov., 2011. Disponível em: <https://educere.bruc.com.br/ CD2011/pdf/4398_2342.pdf> Acesso em 26 ago. 2019.

BARDIN, Laurence. Análise de conteúdo. São Paulo: ediçóes 70, 2011.

BRASIL. Base Nacional Comum Curricular: Ensino Fundamental. Brasília: MEC/ Secretaria de Educação Básica, 2017.

COSTA, Camila e PEREIRA FILHO, E. S. Orientaçóes curriculares e realidades das culturas corporais de movimento na educaçáo física escolar. In: VIII Congresso Sulbrasileiro de Ciências do Esporte, 2016, Criciúma/SC. Anais do VIII Congresso Sulbrasileiro de Ciências do Esporte, 2016.

GRAVATAÍ. Mapa Georreferenciado do Município. Prefeitura Municipal de GravataíRS: Secretaria Municipal de Desenvolvimento Urbano, 2019. Disponível em: <http:// smdur.gravatai.rs.gov.br/mapas.php> Acesso em 6 jul. 2019.

INSTITUTO BRASILEIRO DE GEOGRAFIA E ESTATÍSTICA (IBGE). Pesquisa Nacional por Amostra de Domicílio (PNAD): distribuição da população, por cor ou raça, com indicação do coeficiente de variaçáo, segundo Grandes Regióes e Unidades da Federação. Rio de Janeiro: IBGE, 2018. Disponível em: < População | IBGE>. Acesso em 20 nov. 2020. 
LAKATOS E. M; MARCONI M. A.; Fundamentos da Metodologia Científica. São Paulo: Atlas. 2003.

MORAIS, Carlos. Descrição, Análise e Interpretação de Informação Quantitativa. Escola Superior de Educação - Instituto Politécnico de Bragança, Bragança, Portugal, 2002. Disponível em: <http://www.ipb.pt/ $\sim \mathrm{cmmm} /$ discip/ConceitosEstatistica.pdf $>$. Acesso em 26 ago. 2019.

NEIRA, Marcos Garcia. Incoerências e inconsistências da BNCC de Educação Física. Revista Brasileira de Ciências do Esporte, Porto Alegre, v. 40, n. 3, p. 215-223, set. 2018. Disponível em: <http://www.scielo.br/scielo.php?script=sci_arttext\&pid=S010132892018000300215\&lng=en\&nrm=iso >. Acesso em 18 abr. 2019.

OLIVEIRA, Tânia Modesto Veludo de. Amostragem não Probabilística: adequação de situaçóes para uso e limitaçóes de amostras por conveniência, julgamento e quotas. Fundação Escola de Comércio Álvares Penteado. Administração On Line, v. 2, n. 3, n. p., jul. / ago. / set., 2001.

PEDRA, José Alberto. Uma contribuição ao estudo da representação social da educação escolar no meio rural. Educaçáo em revista., Curitiba, n. 2, p. 65-89, dez. 1982. Disponível em <http://www.scielo.br/scielo.php?script=sci_arttext\&pid=S010440601982000100004\&lng=en\&nrm=iso >. Acesso em 12 abr. 2019.

PEREIRA FILHO, Ednaldo da Silva. Identidades profissionais: marcas de um currículo. Dissertação. (Mestrado em Educação) - Universidade do Vale do Rio dos Sinos. São Leopoldo/RS, 2000.

SOUZA, K. R.; KERBAUY, M. T. M. Abordagem quanti-qualitativa: superação da dicotomia quantitativa-qualitativa na pesquisa em educação. Educação e Filosofia, v. 31, n. 61, p. 21-44, 27 abr., 2017. 